\title{
Concepções de acadêmicos de enfermagem sobre o que é ser enfermeiro
}

\author{
Conceptions of academics of nursing about what is being nurse \\ Concepciones de académicos de enfermería sobre como ser enfermero
}

\author{
Raquel Borba Rosa', Maria Alice Dias da Silva Lima²
}

\begin{abstract}
RESUMO:: O estudo buscou analisar as concepções de acadêmicos de Enfermagem sobre o trabalho do enfermeiro. Através de um questionário com alunos do primeiro, quinto e nono semestres, constatou-se que as respostas dos estudantes do último semestre estão mais próximas da prática concreta, pois esses alunos concebem o enfermeiro como peça chave do trabalho em saúde. Os acadêmicos do primeiro semestre referem-se apenas à dimensão humanitária do trabalho. Os do quinto semestre evidenciam a administração do cuidado e o trabalho em equipe como presentes no cotidiano do enfermeiro. Pode-se afirmar que o ensino desempenha um papel importante na construção das concepções dos alunos, devendo, desde cedo, aproximá-los da realidade da prática profissional.
\end{abstract}

Descritores: Papel do profissional de enfermagem; Estudantes de enfermagem; Educação em enfermagem

ABSTRACT: The study intended to analyze the conceptions of academics of Nursing about the nurse's work. Through a questionnaire with students of the first, fifth and nineth semesters, it was verifyed that the answers of the students of the last semester are closer to the practice of the profission, because these students see the nurse as key of the work in health. The academics of the first semester mention only the humanitarian dimension of the work. And the ones of the fifth semester evidence the administration of the care and the work in group as actual in the daily one of the nurse. It can be affirmed that education plays an important role in the construction of the conceptions of the students, having, since early, to approach them of the reality of the practical professional.

Keywords: Nurse's role; Students, nursing; Education, nursing

RESUMEN: El estúdio buscó analizar las concepciones de académicos de enfermería sobre el trabajo del enfermero. Atravéz de un cuestionario de prospección de opinión con alumnos del primero, quinto y noveno semestres; se constató que las respuestas de los estudiantes del último semestre están en las prácticas concretas, pues esos alumnos ven al enfermero como pieza llave del trabajo en la salud. Los académicos del primer semestre se refieren apenas a la dimensión humanitária del trabajo. Los del quinto semestre evidencian la administración del cuidado y el trabajo en equipo como presentes en el cotidiano del enfermero. Se puede afirmar que el enseñar desempeña un papel importante en la construcción de las concepciones de los alumnos, debiendo desde temprano aproximarlo de la realidad de la práctica profesional.

Descriptores: Rol de la enfermera; Estudiantes de enfermería; Educación en enfermería

\section{INTRODUÇÃO}

Diversos estudos têm sido realizados acerca da finalidade do trabalho do enfermeiro. Alguns autores ${ }^{(1)}$ o reconhecem como facilitador do trabalho dos demais membros da equipe de enfermagem e de saúde. Um estudo ${ }^{(2)}$ evidenciou o predomínio da função gerencial no trabalho do enfermeiro, função essa exercida através da supervisão e controle do processo de trabalho. Apesar disso, os enfermeiros denotam pouca aceitação do caráter gerencial de seu trabalho, tendo como ideal de profissão a assistência direta ao paciente.
A prática do enfermeiro tem sido a de chefiar unidades, elaborar plano de atividades e escala de plantões, prever material e pessoal, supervisionar atividades, revisar as medicações controladas, visitar os pacientes, além de outras atividades. No entanto, as escolas, apesar de enfatizarem as áreas de administração e gerenciamento, não preparam adequadamente as alunas para atuarem com maior segurança e autonomia ${ }^{(3)}$.

Durante os estágios da graduação, o aluno vivencia situações que fogem à realidade da profissão, como o fato de prestar cuidados a um único paciente, alimentando a visão idealizada da assistência direta. Somente no

\footnotetext{
Enfermeira. Mestranda em Enfermagem pela UFRGS. Bolsista CAPES. E-mail: enfquel@hotmail.com

2 Professora Adjunta da Escola de Enfermagem da UFRGS. Doutora em Enfermagem pela USP.
} 
final da graduação é que o aluno passa a ter uma noção mais real sobre o trabalho do enfermeiro, ficando sob sua responsabilidade um maior número de pacientes e algumas atividades de gerenciamento do cuidado. Reconhece-se que tais experiências são necessárias ao aprendizado gradativo do aluno, mas devem ser consideradas as exigências do mercado de trabalho no qual estará esse aluno futuramente, com unidades ou até mesmo hospitais inteiros sob sua supervisão, quando, então, serão cobradas suas habilidades de gerenciamento.

Devido a isso, considera-se necessário conhecer como os alunos concebem sua futura profissão, partindo das experiências e conhecimentos que a graduação lhes proporciona. Parte-se do pressuposto de que o aluno, quando entra no curso de graduação em Enfermagem, traz consigo uma noção idealizada do que é ser enfermeiro. Essa idealização pode ser atribuída à identificação que a sociedade faz do enfermeiro e do trabalho por ele realizado. Um estudo ${ }^{(4)}$, ao analisar reportagens da imprensa escrita, identificou que a referência aos enfermeiros e ao trabalho que exercem está muito ligada à execução da função assistencial, sendo que a atividade gerencial e de planejamento e avaliação dessa assistência não foi evidenciada, bem como as atividades de ensino e pesquisa. Os resultados mostram que a enfermagem é usada como sinônimo de prestação de cuidados e que as reportagens têm contribuído para reforçar estereótipos, sem mostrar à sociedade uma imagem do enfermeiro próxima daquela que os próprios profissionais têm de si mesmos.

Outro estudo ${ }^{(5)}$, sobre a percepção dos enfermeiros de unidade de internação sobre gerência, constatou que os mesmos, em suas primeiras experiências profissionais, chegam com expectativas de trabalhar na assistência e se deparam, na prática, também com atividades burocráticas, o que acaba gerando conflitos. Os resultados apontam para a necessidade de adequação do ensino às exigências do mercado de trabalho, sugerindo a reformulação do currículo, já que os enfermeiros caracterizam as experiências da graduação como insuficientes, fato relacionado à dicotomia existente entre o ensino e a prática. Acrescenta-se que a dissociação entre o que é ensinado e o que o enfermeiro realmente tem condições de realizar em seu cotidiano pode gerar um sentimento de frustração com o trabalho, diminuindo, conseqüentemente, a qualidade dos cuidados prestados ${ }^{(6)}$.

Com base na problemática apresentada, o objetivo geral deste estudo é analisar as concepções que os acadêmicos de enfermagem possuem acerca do trabalho do enfermeiro. Como objetivos específicos, tem-se: comparar as concepções que os acadêmicos possuem, em diferentes momentos da graduação, acerca do trabalho do enfermeiro e analisar se a idéia que fazem desse trabalho condiz com a realidade da prática profissional.

\section{METODOLOGIA}

É um estudo descritivo. Os dados foram coletados através de um questionário com duas questões estruturadas e uma pergunta aberta. Neste artigo são apresentados os dados da questão aberta, que pergunta o que é ser enfermeiro, na opinião dos acadêmicos. $\mathrm{O}$ instrumento foi testado previamente à coleta dos dados, não sendo necessário reformulá-lo.

A coleta dos dados foi realizada no mês de julho de 2003, na Escola de Enfermagem da Universidade Federal do Rio Grande do Sul, com acadêmicos do primeiro, quinto e nono semestres da graduação em Enfermagem da mesma Universidade. A escolha desses semestres justifica-se pelo objetivo da pesquisa de comparar diferentes momentos da graduação, ou seja, os acadêmicos que estão ingressando, trazendo consigo a mesma idéia que a sociedade faz do trabalho do enfermeiro, os que já passaram por alguns estágios (quinto semestre) e os que estão se formando, tendo passado por todas as etapas previstas no currículo. A amostra foi composta pelos alunos que devolveram o questionário corretamente preenchido: 29 acadêmicos do primeiro semestre, 18 do quinto semestre e 34 do nono semestre.

Obteve-se aprovação do Comitê de Ética em Pesquisa da Universidade Federal do Rio Grande do Sul. O aceite em participar foi considerado através da devolução do questionário preenchido pelos acadêmicos. O questionário não exigiu nenhum tipo de identificação, além do semestre que o estudante se encontrava, garantindo o anonimato preservado. Na apresentação dos resultados, os alunos são identificados por códigos: AP (acadêmico do primeiro semestre), AQ (acadêmico do quinto semestre) e AN (acadêmico do nono semestre).

Para tratamento dos dados utilizou-se a técnica de análise temática, que constou de duas etapas: construção de categorias e quantificação do conteúdo. A quantificação do conteúdo implicou em contar o número de vezes em que uma determinada categoria apareceu ou foi omitida ${ }^{(7)}$. Cabe ressaltar que os resultados não são apresentados com as freqüências numéricas com que foram referidos, visto o tamanho reduzido da amostra estudada.

\section{RESULTADOS}

A análise e interpretação dos dados obtidos permitiram a construção de três categorias, representativas da concepção dos acadêmicos sobre o trabalho do enfermeiro: características humanitárias no trabalho do enfermeiro; conhecimento e capacitação para o cuidar; coordenar/organizar/administrar no trabalho do enfermeiro. 
As duas primeiras categorias foram evidenciadas nos três semestres estudados, porém com enfoques diferentes, em vista dos termos que os alunos de cada semestre utilizaram nas suas respostas.

\section{Características humanitárias no trabalho do enfermeiro}

O caráter humanitário da profissão foi muito enfatizado nas concepções dos estudantes. Entretanto, os alunos do primeiro semestre obtiveram predomínio dessas características em suas concepções, expressando os termos "cuidar/cuidado/cuidador" na maioria de suas respostas. Outros termos citados por eles foram "amparar/confortar/ amenizar sofrimento/promover bem-estar", "dedicação/ atenção", "zelar pelo paciente" e "humanismo". Esteve muito clara, em suas respostas, a idéia de doação para o cuidado e abnegação:

Ser enfermeiro é ser cuidador nas 24 horas do dia. (AP-15)

(...) É preocupar-se em viver plenamente como cuidador.

É uma profissão que necessita disponibilidade, amor e disciplina. (AP-5)

Essa concepção humanitária do enfermeiro pode ser atribuída à idealização da profissão. A maioria dos alunos ingressa no curso de graduação em Enfermagem com o pensamento de dedicar a sua vida para ajudar as pessoas, prevalecendo o idealismo como fator importante na escolha da profissão ${ }^{(8)}$. Alguns autores ${ }^{(9)}$ afirmam que

(...) o conceito de Enfermagem antes da graduação é de uma atividade de ajuda, dedicação, devoção e submissão (...).

Um estudo sobre a compreensão que as alunas do segundo período do curso de graduação em Enfermagem têm acerca dos significados da profissão evidenciaram resultados semelhantes aos deste estudo. Entre as categorias identificadas nos discursos das alunas, apareceram o amor ao próximo, a doação ao cuidado e a comparação do enfermeiro a anjos e a super heróis ${ }^{(10)}$. Segundo as autoras, essa visão é perpassada, idealizada, de forma que as alunas tendem a se decepcionar, após conviverem com a realidade do cotidiano que não corresponde as suas percepções.

Ao realizar uma retrospectiva histórica da enfermagem brasileira, percebe-se que esse caráter essencialmente humanitário tem origem na influência que as irmãs religiosas exerciam sobre a profissão. As docentes religiosas exigiam das alunas dos cursos de enfermagem um conjunto de qualidades para ser uma boa enfermeira: se sacrificar pela profissão, coração generoso, tolerân- cia, compaixão, fé em Deus, sendo destacadas a dedicação ao próximo e a renúncia, de forma que o bem-estar do paciente devesse estar acima do próprio bem-estar da enfermeira ${ }^{(11)}$.

Os acadêmicos do quinto semestre expressaram sua concepção sobre o caráter humanitário da profissão sem a idéia de abnegação e doação total, ao contrário dos alunos ingressantes. Entretanto, as características humanitárias também foram as mais citadas por esses alunos. Sua maior preocupação é com o cuidado integral, cujo significado é, para eles, cuidar do paciente vendo-o como um ser humano completo:

Ser enfermeiro é ser cuidador, é zelar pelo próximo, auxiliá-lo quando mais precisa, pois a assistência dada é integral, abrange "corpo", "mente", "alma" (...). (AQ-15)

Ainda, citaram a necessidade de o enfermeiro se dedicar ao conforto e bem-estar do paciente, além de ter empatia pelo mesmo.

Já entre as respostas dos alunos formandos, as características humanitárias também estiveram presentes para descrever o que é ser enfermeiro, mas de forma menos frequiente e com um caráter ainda mais diferenciado. Referiram-se a um cuidado holístico, o qual deve estar voltado para atender necessidades do paciente:

Ser enfermeiro é estar atento às necessidades do paciente. $(\mathrm{AN}-3)$

(...) Cuidar de um paciente vendo-o como um ser humano ‘completo' biopsicossocial (visão holística). (AN - 17)

Sobressaiu, ainda, a idéia de um cuidado mais profissional, interligado a outras atividades, demonstrando a evolução da concepção de cuidado que ocorre com os acadêmicos no progredir da graduação. Expressaram uma preocupação com a questão social e educativa do cuidado.

Ser enfermeiro é prestar cuidados aos clientes, cuidados assistenciais e educacionais (...). ( $\mathrm{AN}-18)$

A concepção de cuidado dos estudantes do nono semestre está associada ao dever da profissão com o ato de cuidar, que é a finalidade da enfermagem.

\section{Conhecimento e capacitação para o cuidar}

A importância do conhecimento para exercer a profissão foi evidenciada, com diferentes abordagens, nas respostas de todos os semestres.

Alguns alunos do primeiro semestre expressaram a importância de o enfermeiro aliar a vocação aos conhe- 
cimentos técnicos ao exercer o cuidado, referindo que ser enfermeiro é

Reunir em si as técnicas e o sentimento de cuidar para desempenhar bem essa função. (AP - 7)

É ser um cuidador nato acoplado a conhecimentos técnicos. $(\mathrm{AP}-2)$

A idéia de vocação para o cuidar pode ser decorrente dos mitos da profissão, de que enfermeiro é aquela pessoa responsável por minimizar o sofrimento do doente, ficando ao seu lado como um "anjo" ou como "mãe", inserindo o trabalho desempenhado pelo enfermeiro em um modelo caritativo ${ }^{(12)}$.

Os estudantes do quinto semestre reconhecem a necessidade e a importância do conhecimento para exercer o cuidado, de forma a embasar as atividades no cotidiano do enfermeiro:

Ter conhecimento científico básico para se dominar os assuntos da saúde (...). (AQ - 1)

A diferença em relação ao primeiro semestre é que esses referiram o conhecimento aliado a uma vocação, um "dom" natural para o cuidar, enquanto que no quinto semestre essa associação não apareceu.

$\mathrm{Na}$ concepção dos alunos do nono semestre, o conhecimento é importante não só para embasar as atividades, mas também a tomada de decisões no cotidiano do enfermeiro:

(...) é tomar decisões rápidas embasadas em conhecimento, tanto em situações de emergência/urgência quanto nas demais. $(\mathrm{AN}-21)$

Evidenciaram, também, a necessidade dos conhecimentos relativos à administração, enfatizando que o "saber administrar" deve visar à qualificação do atendimento prestado:

É usar de conhecimento para administrar uma situação em benefício do usuário/cliente, com o intuito de qualificar o atendimento prestado em saúde. $(\mathrm{AN}-22)$

Os alunos formandos expressaram uma preocupação com o desempenho de seu papel gerenciador. Um estudo $^{(9)}$ com alunos concluintes do curso de graduação em Enfermagem, demonstraram que alguns dos formandos se diziam inseguros frente à necessidade de gerenciar uma equipe, fato que justifica a preocupação relatada pelos estudantes.

\section{Coordenar/organizar/administrar no trabalho do enfermeiro}

Essa categoria foi identificada entre as respostas dos estudantes do quinto e nono semestres.

Nas respostas dos acadêmicos do quinto semestre, a administração do cuidado foi pouco referenciada. Mesmo assim, apontaram a importância de aliar o cuidado às atividades administrativas para $\mathrm{o}$ adequado funcionamento dos serviços.

Ser enfermeiro é auxiliar o paciente (...), proporcionando-lhe um melhor bem-estar. Além disso, é importante cuidar da parte administrativa para que se tenha um bom andamento da unidade. (AQ - 9)

Tal concepção deve-se, provavelmente, ao fato de estarem no meio do curso, já tendo experenciado alguns estágios, nos quais puderam observar o trabalho do enfermeiro. A organização do espaço de trabalho faz parte do gerenciamento do cuidado, para que a assistência prestada seja efetiva. O enfermeiro, quando presente, é o principal responsável pela organização do ambiente assistencial $^{(13)}$. Os estudantes do quinto semestre descreveram algumas situações que necessitam dessa organização:

(...) Fazer com que os procedimentos destinados ao paciente sejam realizados de forma mais eficaz e que eles estejam preparados para exames, cirurgias. (AQ-10)

Também apareceu, entre as respostas do quinto semestre, o trabalho junto à equipe de saúde, evidenciando a idéia do trabalho coletivo, o qual permite ao enfermeiro atuar na reabilitação do paciente, junto à equipe de saúde:

Ser enfermeiro é (...) interagir com outros profissionais da área da saúde (...). (AQ - 7)

Ajudar no processo de cura do paciente (...). (AQ - 10)

Apesar de evidenciarem e reconhecerem as atividades administrativas como importantes no trabalho do enfermeiro, os alunos do quinto semestre ainda o fazem de forma incipiente.

Já entre as concepções dos alunos formandos, essa foi a categoria predominante, sendo que a referência às atividades de gerenciamento e administração apareceu em quase todas as respostas desses estudantes. Apenas cinco deles não relataram essas atividades como integrantes do trabalho do enfermeiro. Além disso, demonstraram uma concepção mais abrangente e detalhada acerca desse trabalho e das atividades administrativas presentes no mesmo. Priorizaram, em suas respostas, a assistência, se referindo ao cuidado humano como sen- 
do a atividade do enfermeiro. Mas para que esse cuidado e a assistência prestada sejam qualificados, enfatizaram a importância da administração do cuidado:

Ser enfermeiro é prioritariamente cuidar do paciente de forma humanizada. É também administrar uma unidade para que isso ocorra (o cuidado) da melhor forma possível. $(\mathrm{AN}-10)$

É conciliar atividades administrativas e assistenciais garantindo a recuperação e promoção da saúde dos pacientes/clientes, além de facilitar o andamento adequado do trabalho em equipe. $(\mathrm{AN}-14)$

As atividades de coordenação da equipe de enfermagem também estiveram presentes nas concepções dos formandos. O trabalho de enfermagem, por ser desenvolvido por mais de uma categoria profissional, ocorre através de operações hierarquizadas. Configura-se, portanto, como um trabalho coletivo, que precisa ser coordenado e gerenciado por alguém ${ }^{(14)}$.

(...) habilidade de lidar com o outro, orientar e supervisionar, (...), avaliar o serviço e funcionários, realizar reuniões periódicas, escalas de folgas e férias. $(\mathrm{AN}-24)$.

Essa concepção condiz com resultados de uma pesquisa $^{(2)}$ que verificou que os enfermeiros têm exercido, principalmente, atividades de coordenação, supervisão e controle do trabalho, em unidades de internação.

A posição de centralidade que o enfermeiro ocupa e seu papel como "peça chave" na equipe de saúde foi evidenciada por alguns acadêmicos do nono semestre. A centralização de informações faz com que o enfermeiro torne-se um "elemento de referência" no espaço onde atua, tanto para os demais profissionais como para os familiares dos pacientes ${ }^{(13)}$. $\mathrm{O}$ enfermeiro detém o monopólio das informações, tanto relativas à dinâmica do trabalho quanto aos processos desenvolvidos com todos os pacientes sob sua responsabilidade. Alguns dos acadêmicos do nono semestre expressaram a necessidade do enfermeiro deter todas as informações acerca de seus pacientes, como descreveu este acadêmico:

É estar a par do quadro de saúde de todos os pacientes internados em seu setor (...). (AN - 25)

Em algumas situações o enfermeiro é percebido como alguém capaz de resolver os problemas que surgem, além de atuar como facilitador do trabalho para os demais membros da equipe ${ }^{(13)}$. Os estudantes expressaram essa concepção:
Ser enfermeiro é ser a "válvula de escape" de toda a equipe. Todos os problemas que surgem na unidade acabam na responsabilidade do enfermeiro em resolver; os funcionários esperam isso deste profissional (...). ( $\mathrm{AN}-16)$

Alguns dos formandos consideraram a importância do trabalho em equipe para o desenvolvimento da assistência ao paciente:

(...) É trabalhar em equipe, de forma integrada e interdisciplinar. (...) Precisa gostar e saber agir em equipe. $(\mathrm{AN}-33)$

Já foi constatado que o trabalho do enfermeiro é composto por múltiplas atividades ${ }^{(15)}$. Na concepção de alguns acadêmicos do nono semestre, essa característica também foi evidenciada, conforme expressou este estudante:

Ser enfermeiro é administrar uma unidade, é estar preocupado com "todas" as situações. Um enfermeiro assume atividades de diferentes naturezas, administrativas, assistenciais, educativas e de pesquisa. Popularmente se diz que um enfermeiro é um psicólogo, mãe, nutricionista, amigo, etc. (AN-9)

As diferentes atividades que o enfermeiro desenvolve em seu cotidiano evidenciam a multidimensão característica de seu trabalho. Os sujeitos do nono semestre expressaram essa multidimensionalidade ao citar atividades de diferentes naturezas para descrever o que é ser enfermeiro. Ficou claro, entretanto, nas concepções desses alunos, que as atividades que integram o trabalho do enfermeiro, mesmo as de cunho administrativo, atendem a uma finalidade maior: a qualidade do cuidado ao paciente.

\section{CONSIDERAÇÕES FINAIS}

Pôde-se evidenciar a presença de características humanitárias nas respostas dos alunos dos três semestres estudados, quando descreveram o que é ser enfermeiro. Entretanto, os acadêmicos de cada semestre apresentaram enfoques diferentes em suas concepções. As respostas dos alunos do primeiro e do nono semestres foram as que mais se diferenciaram, quando comparadas.

Os alunos do primeiro semestre ainda possuem uma visão vaga e idealizada do trabalho desse profissional, referindo-se apenas à dimensão humanitária, acompanhada de idéias de doação para o cuidado e abnegação, características essas que estão distantes da realidade da prática profissional. Ainda, expressaram que existe uma vocação para o cuidar, a qual deve estar aliada aos conhecimentos técnicos. Os acadêmicos do quinto e do 
nono semestres também evidenciaram a importância dos conhecimentos para exercer a profissão, porém não citaram a vocação.

Os estudantes do quinto semestre demonstraram uma concepção menos idealizada do trabalho desempenhado pelo enfermeiro, se referindo, principalmente, ao cuidado integral, mas sem expressar a doação total e abnegação. Evidenciaram, ainda que de forma vaga, a administração do cuidado e o trabalho em equipe.

Por fim, as respostas dos alunos do nono semestre expressaram concepções ligadas ao dever da profissão com o ato de cuidar para atender necessidades não só do paciente, mas necessidades sociais. Apresentaram, além disso, uma noção mais aprofundada da atividade de gerenciamento no trabalho do enfermeiro. Referiram-se à administração do cuidado em mais da metade de suas respostas, e à coordenação da equipe de enfermagem. Concebem o enfermeiro como "peça chave" do trabalho em saúde, que centraliza informações e é capaz de resolver diferentes problemas que surgem no espaço onde atua. Ainda, evidenciaram o trabalho junto à equipe de saúde e a presença de múltiplas atividades no cotidiano de trabalho do enfermeiro.

Comparando as concepções dos alunos com resultados de estudos sobre o trabalho do enfermeiro, podese considerar que as do nono semestre são as que mais se aproximam da prática concreta desse trabalho, visto que o quinto e, principalmente, o primeiro semestre ainda possuem visões restritas. E, considerando que as concepções dos acadêmicos sobre sua futura profissão traduzem as vivências que têm na graduação, pode-se afirmar que o ensino desempenha um papel decisivo na construção dessas concepções, devendo, desde cedo, aproximar os alunos da realidade da prática profissional.

\section{REFERÊNCIAS}

1. Lunardi VL, Lunardi Filho WD, Borba M.R. Como o enfermeiro utiliza o tempo de trabalho numa unidade de internação. Rev Bras Enferm 1994; 47(1):7-14.

2. Lima MADS. O trabalho de enfermagem na produção de cuidados de saúde no modelo clínico. [tese]. Ribeirão Preto (SP): Escola de Enfermagem de Ribeirão Preto/USP; 1998.

3. Waldow VR. Cuidado humano: o resgate necessário. Porto Alegre: Sagra Luzzatto; 1998.

4. Sanna MC, Secaf V. A imagem da enfermeira e da profissão na imprensa escrita. Rev Enferm UERJ 1996;4(2):170-82.

5. Sette VM, Silva AX, Da Costa MC, Schweber R, Echer IC. Percepção dos enfermeiros de unidade de internação sobre gerência. Rev Gaucha Enferm 1997; 18(1):54-62.
6. Magalhães AM, Juchem BC. Atividades do enfermeiro em unidade de internação cirúrgica de um hospital universitário. Rev Gaucha Enferm 2001; 22(2):102-21.

7. Cortes SMV. Técnicas de coleta e análise qualitativa de dados: pesquisa social empírica: métodos e técnicas. Cad Sociol 1998; 1(9):11-47.

8. Oguisso T, Seki LK, Araújo GL, Shibuya CA, Speciale C, Trovo MM. Enfermagem: idealismo X realismo: perspectivas de formandos do curso de graduação de enfermagem sobre a profissão de enfermagem. Rev Esc Enferm USP 2001; 35(3):271-81.

9. Júnior JGCS, Cavalcanti ATA, Monteiro EMLM, Silva MI. Como será o amanhã? Responda quem puder! Perspectivas de enfermeirandos quanto ao seu futuro profissional. Rev Bras Enferm 2003; 56(4):453-8.

10. Padilha MICS, Nazario NO, Moreira MC. A compreensão do ideário da enfermagem para a transformação da prática profissional. Rev Bras Enferm 1997; 50(3):307-22.

11. Ribeiro AAA, Boreinstein MS. Escola de Enfermagem Wenceslau Braz: trajetória e construção da identidade profissional da enfermagem em Itajubá/MG. Texto Contexto Enferm $2003 ; 12(4): 470-8$.

12. Gustavo AS, Lima MADS. Idealização e realidade no trabalho da enfermeira em unidades especializadas. Rev Bras Enferm 2003; 56(1):24-7.

13. Lunardi Filho WD. O mito da subalternidade do trabalho da enfermagem à medicina. Pelotas (RS): Editora Universitária/ UFPEL; 2000.

14. Lunardi Filho WD, Lunardi VL. Uma nova abordagem no ensino de enfermagem e de administração de enfermagem como estratégia de (re)orientação da prática profissional do enfermeiro. Texto Contexto Enferm 1996; 5(2):20-34.

15. Lima MADS, Gustavo AS, Coelho DF, Schmitz UV, Rosa RB. Concepções de enfermeiras sobre seu trabalho no modelo clínico de atenção à saúde. Rev Bras Enferm 2000; 53(3):343-54. 